\title{
Using Social Media as One of Learning Tool: Facebook Enhances Learning Practices among Higher Learning Students in Malaysia
}

\author{
ASLINDA MOHD SHAHRIL \\ Universiti Teknologi MARA, Selangor branch, Puncak Alam Campus, Malaysia. \\ Email: shahrilas74@gmail.com \\ Phone: +60 132771590 \\ RASIDAH HAMID \\ Universiti Teknologi MARA, Selangor branch, Puncak Alam Campus, Malaysia. \\ SABRINA TARMUDI \\ Universiti Teknologi MARA, Selangor branch, Puncak Alam Campus, Malaysia. \\ CHEMAH TAMBY CHIK \\ Universiti Teknologi MARA, Selangor branch, Puncak Alam Campus, Malaysia.
}

ISMAYAZA NOH

Universiti Teknologi MARA, Selangor branch, Puncak Alam Campus, Malaysia.

\begin{abstract}
Higher learning institutions are beginning to embrace social media and realizing the potential power and implications for a new learning model. The emergence of social media has impacted significantly on how students learn and the way instructors teach and share knowledge and information. This study was conducted at Faculty Hotel and Tourism Management, Selangor branch, Puncak Alam campus, Universiti Teknologi MARA, Malaysia. Respondents for the study were first year undergraduate students who enrolled in Housekeeping course. This study would like to obtain information and feedback from the students on the new teaching and learning approaches using social media, particularly Facebook as a learning tool in terms of its usefulness and ease of use. An interview was conducted to 35 respondents and it was found that Housekeeping page created on Facebook is useful and convenient to the students based upon the students' deliberations. Students confirmed that using social networks increased both enthusiasm for learning and motivation and should be one of the current educational settings. This study highlights the importance of social media and educators in higher learning institutions should take this opportunity to join and connect with these technologies that are already integrated into students' daily lives and to design an innovative and creative educational environment.
\end{abstract}

Keywords: Higher Learning Institution, Social Media, Facebook, Learning Tool, Innovative, Creative.

\section{Introduction}

In Malaysia, teaching and learning innovation is one of the strategies that is included in National Higher Education Strategic Plan (NHEAP) 2015-2020. A well-designed higher education curriculum should 
include creativity and innovation to enhance student learning experience (Grapragasem, Krishnan, Mansor, 2014).

Virtual classroom, mobile learning and social media tools are fast gaining momentum and has also changed the delivery style of teaching and learning. A study conducted by Masrom, Nadzari, Mahmood, Zakaria and Ali (2016) on mobile learning and social media in Malaysia's higher learning institution indicated positive impact to deliver information to students and is required in Malaysia.

The conventional method of delivering knowledge through face-to-face interaction, lecturing and spending most times in classrooms is slowly taking a step backward, even though it is still widely used in public and private colleges and universities in Malaysia. Problems associated with traditional approaches to teach have been well-documented. The usual problems with a one-way system of lecture delivery are recognized and they emphasize the lack of experiential learning in a usual class environment (Dawson, 2000) and deficiency of creativity and innovative teaching and learning style.

The one-dimensional way of learning is way over. Educators commented on how a course may seem uninteresting and unpleasant to students. It results to students' lack of motivation and self-discipline (Pieroni, Vuano, \& Ciolino, 2000). On the other hand, virtual classrooms, e-learning, mobile learning are slowly gaining momentum in education system.

Therefore, it calls for a new learning model and not to be too depending on the current teaching and learning style which applies only one-way system but to encourage and explore creative, innovative and attractive learning and to energize the traditional approach of learning in higher learning institutions system in Malaysia.

\section{Literature Review}

Increasingly, due to global competition, new technology innovations and digital media have made significant impact and improvement on the general population lives in the whole world. The impact also applies for learning and training in education. According to Lee (2011), teaching innovation is the top priority mission when challenged by global competition because of innovation is an assurance to enhance competitiveness and can be greatly cultivated through education. In order for students to be creative, teaching must be innovative to improve the learner's innovative capability.

\section{Social Media Trends in Education}

Nowadays, students are digital technology natives with great sophistication in the usage and potential of social media. Furthermore, smartphones have been widely used among students that enable them to access various applications easily including browsing and engaging with social media activities. Generally, Social Media Technologies (SMTs) can be categorised into several functions; text-based, social networking, mobile-based applications, synchronous communications and conferencing applications (Lim, Agostinho, Harper, Chicharo, 2013). All these tools have different functions and purposes to suit the needs of students in this digital environment. Students can take advantage of these various functions in their own personal learning communities which would allow them to stay connected in the topic of their interest. When social media technologies emerged in the market, students quickly bond themselves to those tools such as YouTube, Facebook, Instagram, blogging and twittering.

Social media and the Web 2.0 tools have become "the enablers that bring the learning community together, however it is defined by the learner, and provides the framework that allows online learners and teachers to harness the power of collaborative, personal learning" (Powers, et al., 2012). The influence of social media on learning and teaching environments is growing more each year. The emergence of social media has impacted significantly on how students learn and the way instructors teach and provide materials and 
information. The task of knowledge construction is thus being shared among the instructor, students, and other individuals who share an interest for the subject.

Social media is a potential powerful tool in education where the applications can reinforce class material and positively influence discussions. Therefore, it is necessary to switch from the traditional lecture and questions/answers approach to better use the various social media tools available nowadays to meet students' needs and expectations and this trend has gained much attention, participation and interest from students and instructors as well.

A study conducted by Delello, McWhorter, and Camp (2015) found that students' use of social media was viewed as a beneficial tool to classroom learning. The study suggested that that educators must continue to find ways to relate to students because a "disconnect" currently exists between the teaching and learning taking place within classrooms. Bozarth (2010) suggested instructors to apply social media in the classroom because "technologies dissolve many of the barriers between the learners and the instructor, creating a more informal, collegial, and interactive learning environment" (p. 13).

Initially, the features in social media such as Facebook were not developed for teaching and learning purposes as many people used it for social interaction and recreational purposes. Hew (2011) found that Facebook was very little educational use because many perceived it as a tool to just keep in touch with friends. However, many of these social media provide platform for users to exchange information, sharing informative knowledge and interesting apps and videos which can be used in teaching and learning that provides innovative way in sharing and delivering knowledge. Therefore, many instructors in education system take this opportunity to deliver and share knowledge and course information using this social media that could enrich learning experience among students. This effort is supported by Miloservic (2015) study on the use of Facebook by Serbian students and found that communication between students and professor have improved and support the educational process.

In today's higher learning settings, instructors, students, and others collaborate on the tasks of knowledge construction. These needs include increased access to the instructor and fellow students as well as courserelated project data and information. In evaluating full potentials of social media, knowing how and why students are using the social media tools, are important for teachers to enable them to effectively integrate these learning tools in teaching.

Lepi (2012) identified some ways in which teachers can integrate social media as a learning tool. Facebook, for example, has the following features: user's profile, status, friends, news feed, wall, discussion boards, unlimited videos duration and applications. Based on these features, Facebook provides tool for building a sustainable and life-long learning social network and share interesting information between its users. Another social media such as Twitter can be used to post supplementary materials like links to articles and videos while Instagram is another social media platform that allows teachers and students to easily share images with each other. On the other hand, YouTube is a popular free video sharing service that can be used by students as a tool for their video project presentations and for teachers to upload teaching materials for their students.

For the purpose of this study, Facebook is chosen among other social media because all students in this study setting; first year undergraduate students from Faculty of Hotel and Tourism Management, Universiti Teknologi MARA, Selangor branch, Puncak Alam campus, Malaysia should have Facebook account that feed them with various information of faculty's academic activities and information. Everyone in the faculty has Facebook including students, lecturers, the faculty, and also the university itself.

Interestingly, Facebook have all sorts of student and instructor information, including photos about themselves and their networking groups. The established personal profile can be used as a tool for icebreaking, so that students and instructor can get to know each other in much more depth than a simple 
self-introduction in a class. Additionally, the wonderful part of using Facebook as a community learning tool is the continuity after the academic semester is over.

The objectives of this study are to attain feedback and opinion from students the teaching and learning approaches in new way, using social media, particularly Facebook, in providing and sharing all information between instructor and students. Specifically, it aims at answering the following research objective: 1) To acquire the student's feedback on the use of Facebook as a learning tool in terms of its usefulness and ease of use.

Additionally, this effort is to support and inspire faculty to step outside of traditional boundaries of teaching to improve student's learning styles. Furthermore, it presents creative and innovative way to engage students in learning and to enhance academic experience. Finally, little empirical evidence has been reported on the potential usage of social media in enhancing student's learning experience in higher learning institutions in Malaysia. It is hoped that this study will provide interesting findings and enhance the contribution to the current body of knowledge.

\section{Importance of the Study}

There is limited research focused on social media, particularly Facebook for teaching and learning use in the higher learning classroom in Malaysia. Thus, this study aimed to investigate and to gain information from students how social media is useful and effective in promoting learning in the classroom and enhance their higher learning experience. 35 undergraduate students from Faculty of Hotel and Tourism Management, Universiti Teknologi MARA, Selangor branch, Puncak Alam campus, Malaysia that utilised social media for learning were selected for this study. These reflective data may serve useful for future studies and suggest important avenues necessitating further research.

\section{Methodology}

In order to realise the full potentials of social media, it is important to know student's opinions in using the social media tools. For the purpose of this study, a private Facebook page was created, and the first year undergraduate students taking up Bachelor of Hotel Management at Faculty Hotel and Tourism Management, Universiti Teknologi MARA who enrolled Housekeeping course were invited to join the page. The Facebook page, named 'HOUSEKEEPING MANAGEMENT', provides students with all sorts of information such as notes, photos, videos, online assignments and other related information about the course. Students were instructed to join the group and used it for eight weeks. 35 students consist of 23 females and 12 males joined the group and used it at their convenient time.

Clear instruction and explanation were given in order for the students to safely use it as educational purposes. The instructor automatically knew all respondents who joined the created page since they needed approval to join and they have to complete online assignment given to them, therefore the total number of assignments sent represent the number of respondents. It was found that the students quickly requested for the account approval and embrace all the activities provided in the 'HOUSEKEEPING MANAGEMENT' Facebook page. The students were allowed to use the account for the purpose of sharing information and activities of the course in the given time. An important observation was carried out and that is the students grew from less motivated and passive learners to active and dynamic.

By the end of eight weeks, an interview was arranged and the interview questions which were derived from the student's feedback and opinion was: 1) What are the student's feedback on the use of Facebook as a learning tool in terms of its usefulness and ease of use?

The interview was conducted during December 2018 and it was done at the faculty and it took about two weeks to complete the interview process. 


\section{Results}

After collecting and transcribing all information during the interview session, the study found that HOUSEKEEPING MANAGEMENT page created on Facebook is useful and convenient to the students based upon the students' deliberations.

Based on the interview session, all students took part on the activities posted on Facebook and they like the use of social media as one of the class activities. They said that it was more interesting than the traditional approach where information is being discussed in class. They also added that it enhanced their learning experience. According to them, they are motivated to open their Facebook daily and engaged with the activities. On the other hand, the instructor found that the students completed their online assignment earlier than the given time.

Among the valuable comments received form the students:

Comment 1:

"I love this learning style. It is interesting and fun. It motivates us to do our assignment without delay. We are technology savvy and we find this easy and convenience. Awesome!"

\section{Comment 2:}

"Facebook is great tool for discussion with other classmates. It does not have space limit and we could post many videos, especially about bed-making and how to clean a room. This is important for our revision before mid-term test."

\section{Comment 3:}

"We think other courses should use this learning technique. This is innovative learning style. We can assess Facebook 24 hours a day and do our assignment at any time... mmm.. even after 12 midnite and submit to lecturer right away. We have update information because another groups will immediately post their activities after the class. We also enjoy to see pictures of other members with their family. We feel connected."

\section{Comment 4:}

"We have smartphone, so we don't have problem to log in anytime. While waiting for class, we can still do our online assignment and send it much earlier. We can also watch the videos posted by our friends and comment immediately. So easy."

It was found that students could easily contact one another regarding discussion in class, case studies, individual and group assignments. Facebook platforms provided a collaborative learning environment in which students were able to share information, communicate and cooperate with each other during the completion of the given task. On the other hand, there were students that did not participate regularly in class due to lack of communication skills and they felt they can express their thoughts on our Facebook page. Although this should not completely replace class participation, it can help build the students' confidence and encourage them to find their voice and be able to participate regularly.

Additionally, participants who have questions about class assignment can easily post a message asking if anyone could give suggestions and offer some assistance. They could also write a specific question to the instructor or admin of the Facebook page on a wall that others can read. This allows the whole class to have access to the feedback from the instructor. Furthermore, resources can be shared quickly on Facebook page. 
This is in line with Delello, Mcwhorter and Camp (2015) suggestions that one of the benefits of social media in the classroom is its potential for viral marketing, meaning the voluntary sharing of material among users. This is also in line with Facebook mission "to give people the power to share and make the world more open and connected" (Facebook, 2012).

None of the students reported boredom or unhappy with this style of learning. Students declared that using social networks increased both enthusiasm for learning and motivation thus confirmed previous study findings that social media may be one of the golden ticket to provide students with meaningful, connected learning experiences and this could offer new method for innovative and creative teaching and learning style. Finally, the overall opinion was favorable acceptance of using Facebook and this has motivated the instructor to create another page for other courses.

\section{Discussion}

While social media continue to advance, the functions and uses have changed and expanded from being just an online platform for socialization to a potentially powerful tool for teaching and learning. The findings of the study revealed that in general, students loved to engage themselves with social media and they found it interesting to be part of the socialization and learning tool. It can be said that the use of social media energizes the traditional teaching and learning approach. This finding is in line with Delello et al. (2015) that social media can add value to current teaching and learning approach. It was also found that the transition of this learning approach enhances the interaction between the instructor and students.

Therefore, this study supports Malaysia National Higher Education Strategic Plan (NHEAP) 2015-2020 that higher learning curriculum should include creativity and revolution to enhance students' learning experience. It can be said also that higher learning is in the process of revolution and educators are starting to think outside the box, offering new and fun way delivering and sharing knowledge with students.

Students in this generation embrace social media and realize the potential power and implications for using it as not only socialising but the potential to offer new types of student engagement and educational settings. The use of social media in higher learning institutions is becoming critical as the use of these tools and technologies has been the chunk of current students' lifestyles. Educators in higher learning institutions should take this opportunity to join and connect these technologies that are already integrated into students' daily lives to design an innovative and creative education environment that will enhance and improve their learning experiences.

\section{Limitations}

Some limitations associated with this study should be put into consideration. The first limitation of the study where data were collected from only one campus branch of the university. Second, the use and application of social media limited to only one course, Housekeeping and did not apply to other courses. For sample limitation, the respondents were the first year of undergraduate students and this study did not collect information from the second and final year students. Therefore, more students might be included in future studies. In terms of research design, this study employed interview as a mean to obtain data, whereas employing a mixed method might have greater impact on the results of the study. Future research should consider using both methods to gain more vigorous findings.

\section{Direction for Future Research}

More additional studies can be carried out to further investigate the area and scope of the study so that better research can be conducted in the future. This type of study is relatively new in higher learning in Malaysia, future studies may further enrich the body of knowledge on the potential of social media in higher learning. One important note that future research should include is other types of social media such 
as blogs, Twitter and others and investigate its potential to enhance student learning experience. In terms of sample selection, future study should include more students from other branches using the same model of current study and provide interesting findings.

\section{Acknowledgement}

The authors would like to thank Universiti Teknologi MARA for their support in making this project possible. This work was funded by the LESTARI Grant, Universiti Teknologi MARA.

\section{References}

Bozarth, J. (2010). Social media for trainers: Techniques for enhancing and extending learning, San Francisco, CA: John Wiley \& Sons, Inc

Facebook (2012). Mission. In Facebook, Retrieved June 16, 2012 from https://www.facebook.com/facebook?sk=info

Hew, K. F. (2011). Students' and teachers' use of Facebook. Computers in Human Behavior, 27(2), 662676. http://doi.org/10.1016/j.chb.2010.11.020

Liu, Y. (2010). Social media tools as a learning resource. Journal of Educational Technology Development and Exchange, 3(1), 101-114.

Griesemer, J.A (20) Using Social Media to Enhance Students' Learning Experiences. Quality Approaches in Higher Education 3(1)

Myra Collado Almodiel (2017) ASEAN Journal of Open Distance Learning, 9(2)

Powers, L., Alhussain, R., Averbeck, C., \& Warner, A. (2012). Perspectives on distance education and social media. Quarterly Review of Distance Education, 13(4), 241-245.

Lepi, K. (2012, July 28). 25 Ways teachers can integrate social media into education. Retrieved from: http://edudemic.com/2012/07/a-teachers-guide-to-social-media/.

Delello, J.A , Mcwhorter, R.R , Camp, K.M. (2015) Using Social Media as a Tool for Learning: A MultiDisciplinary Study . International Jl. on E-Learning, 14(2), 163-180

Milosevic, I., Zivkovic, D., Arsic, S., \& Manasijevic, D. (2015). Facebook as virtual classroom - Social networking in learning and teaching among Serbian students. Telematics and Informatics, 32, 576585. http://doi.org/10.1016/j.tele.2015.02.003

Lim, J.S.Y , Agostinho, S. , Harper, B. and Chicharo, J.F. (2013) Investigating The Use of Social Media by University Undergraduate Informatics Programs. Malaysia International Conference on Educational Technologies. 